NBER WORKING PAPER SERIES

\title{
THE IMPACT OF COMPARATIVE EFFECTIVENESS RESEARCH ON HEALTH AND HEALTH CARE SPENDING
}

\author{
Anirban Basu \\ Tomas J. Philipson \\ Working Paper 15633 \\ http://www.nber.org/papers/w15633 \\ NATIONAL BUREAU OF ECONOMIC RESEARCH \\ 1050 Massachusetts Avenue \\ Cambridge, MA 02138 \\ January 2010
}

We are thankful for comments from the referees and the editor Tom McGuire and research assistance from Cindy Yuan . In addition, we appreciate the comments from seminar participants of the 2009 Annual Health Economics Meeting, the NBER 2010 Health Care Meetings, the 2010 ASHE Meetings, The 2010 AdvaMed Meetings, the University of Chicago, Rice University, University of Houston, and the Wharton School. Dr. Basu acknowledges support from a research grant from the National Institute of Mental Health, 1R01MH083706 - 01. Dr. Philipson acknowledges support from the Stigler Center for Study of the Economy and the State at the University of Chicago as well as the National Pharmaceutical Council. The statements, findings, conclusions, views, and opinions contained and expressed in this article are based in part on data obtained under license from the following IMS Health Incorporated information service(s): National Disease and Therapeutic Index ${ }^{\mathrm{TM}}$ (2003-2008), IMS Health Incorporated. All Rights Reserved. The statements, findings, conclusions, views, and opinions contained and expressed herein are not necessarily those of IMS Health Incorporated, any of its affiliated or subsidiary entities, or the National Bureau of Economic Research.

NBER working papers are circulated for discussion and comment purposes. They have not been peerreviewed or been subject to the review by the NBER Board of Directors that accompanies official NBER publications.

(C) 2010 by Anirban Basu and Tomas J. Philipson. All rights reserved. Short sections of text, not to exceed two paragraphs, may be quoted without explicit permission provided that full credit, including (c) notice, is given to the source. 
The Impact of Comparative Effectiveness Research on Health and Health Care Spending Anirban Basu and Tomas J. Philipson

NBER Working Paper No. 15633

January 2010, Revised November 2010

JEL No. I0,I1,I11,I18

\begin{abstract}
$\underline{\text { ABSTRACT }}$
Public technology assessments in general and Comparative Effectiveness Research (CER) in particular have been justified by offsetting benefits of improving patient health and reducing health care spending. However, little conceptual and empirical understanding exists concerning the quantitative impact of public technology assessments such as CER. This is needed to assess whether CER has benefits that outweighs its investment costs. This paper provides a systematic framework to analyze the impact of CER on health outcomes and medical care spending. We interpret CER to infuse evidence on product quality into the market place declaring product winners and losers. This shifts demand by patients and doctors as well as coverage by third party payers towards the winners of CER studies and away from losers. We trace out the spending and health implications of such responses to evidence on product quality in privately and publicly financed health care markets. We simulate these effects for antipsychotics that are among the largest drug classes of the US Medicaid program and for which CER has been conducted by means of the CATIE trial in 1999. Our main conclusion, from both the conceptual and empirical analysis, is that investments into CER may not always have the intended benefits of lowering spending and improving health outcomes. Because CER may result in higher spending and worse health, it is important to have methods to evaluate quantitatively the impacts of CER investments.
\end{abstract}

\author{
Anirban Basu \\ Section of of Hospital Medicine \\ Department of Medicine \\ University of Chicago \\ 5841 S. Maryland Avenue \\ MC-2007, AMD B226C \\ Chicago, IL 60637 \\ and NBER \\ abasu@medicine.bsd.uchicago.edu \\ Tomas J. Philipson \\ Irving B. Harris Graduate School \\ of Public Policy Studies \\ The University of Chicago \\ 1155 E 60th Street \\ Chicago, IL 60637 \\ and NBER \\ t-philipson@uchicago.edu
}




\section{Section 1: Introduction}

The debate about the appropriate role of public technology assessments has a long history in the US. ${ }^{1}$ More recently, as both private and public payers attempt to improve the efficiency of health care spending, comparative effectiveness research (CER) has been offered as a potential solution. The rationale for CER is that better evidence about what works and does not work in health care can improve the productivity of health care spending through improved patient outcomes at lower spending levels. (FCCCER Report 2009; IOM 2009) Moreover, recent public subsidization of CER through the 2009 American Recovery and Reinvestment Act (ARRA) has raised awareness and funding for CER.

However, although CER has been positioned as a means to improve health and potentially lower costs, little is understood about how exactly this will take place and how the infusion of evidence into health care markets through CER studies will translate into different health care decisions. Despite the emphasis placed on publicly subsidized evidence being infused into the market place, and CER in particular, there has been little explicit and quantitative analysis of the potential impact it may have on health or medical care spending. Indeed, little is understood about the conditions necessary for CER to have its intended effects. Given this lack of understanding of the impact of CER, the purpose of this paper is to attempt to provide a framework to quantitatively evaluate, in a consistent and systematic way, the effects of CER.

The paper may be outlined as follows. Section 2 specifies the economic context in which we analyze the impact of public technology assessments such as CER. We interpret the infusion of evidence generated by public subsidies for CER as an increase in the demand for some treatments at the expense of others. This section also considers the health- and cost implications of such CER-induced demand shifts in a private market as sales of winners of CER studies rise and the corresponding sales of losers fall. Indeed, changes in sales due to changes in quality evidence are frequent in medical product markets. For example, following the reports of the potential side effects of Avandia in 2007, it was reported that new prescriptions fell by about 40 percent $^{2}$.

Section 3 analyzes these impacts in a subsidized market where the treatments that fare better under CER are the ones that receive better coverage, e.g. through less formulary restrictions, changes in prior authorization requirements, or lower co-pays. Thus, we perceive two responses by the market to the infusion of CER findings: the first is by patients and doctors and the second, potentially lagged, is by third-party payers, whether public or private.

Section 4 discusses the impacts of CER-responsive coverage decisions when there is heterogeneity in treatment effects. An important issue here is that CER may favor one treatment, deemed "the best" by

\footnotetext{
${ }^{1}$ They date back at least to the 1970s with the National Center for Health Services Research and the US Congress Office of Technology Assessment. See Malani and Philipson (2010) for a more detailed discussion.

${ }^{2}$ Wall Street Journal Online (http://online.wsj.com/article/SB118545484246978888.html).
} 
some summary statistic, even though the best treatment varies across patients. This implies that when coverage responds to the new CER evidence, some patients face higher prices for their best therapy while other see price reductions. This leads to an indeterminate effect on health outcomes.

Section 5 provides an illustrative empirical simulation of the discussed effects. We consider Medicaid coverage changes due to recent CER evidence in the case of antipsychotic drugs. This drug class is among the top spending classes overall and particularly in Medicaid. After the results of a CER study in 2006, the CATIE trial, there has been considerable debate about changing coverage due to the evidence generated. Using the observed heterogeneity in treatment effects from the CATIE trial, we quantify the discussed indeterminate impact on health if Medicaid were to respond in coverage to the CER by only covering the antipsychotic deemed most cost-effective in the CER. In such a case, we find that negative impact on health outcomes surpasses the reduction in spending by an amount valued at $5 \%$ of class spending.

Our main conclusion therefore, from both the conceptual and empirical analysis, is that investments into CER, as it is currently practiced, may not have the intended benefits of lowering spending and improving health outcomes. This occurs under fairly natural economic predictions of how markets respond to the infusion of new quality information. We conclude in section 6 by discussing future research in the area of quantitative evaluation of CER and how such analysis may inform the development of improved methods for CER.

\section{Section 2: Impact of Effectiveness- and Comparative Effectiveness Studies in a Private Market}

This section specifies the framework in which health and spending implications are analyzed. We first discuss the impact of effectiveness evidence on spending and health for a single product ${ }^{3}$ and then expand the analysis to consider CER for multiple products.

\section{1: Effectiveness Evidence, Spending and Health Outcomes}

Consider first when there is a single product priced at $p$ with true the true quality or effectiveness $q$, representing its treatment effect relative to the alternative, normalized to have zero quality ${ }^{4}$. We represent the effectiveness evidence by a scalar $e$ for which higher values are more favorable evidence, e.g. this scalar could represent the sample mean of health outcomes in a

\footnotetext{
${ }^{3}$ Pauly and Blavin (2008) discusses related normative aspects of treatment coverage under insurance.

${ }^{4}$ Throughout, we discuss health effects concerning this measured health outcomes. However, overall health effects may differ if substitution occurs across health behavior or products with changes in demand of the discussed treatment.
} 
randomized trial against the status quo treatment. We let $D(p, e)$ denote the demand function for the product given the evidence about product quality. We assume that better demonstrated effectiveness raises demand, $D_{e}>0$, but does not affect supply.

To illustrate such a demand function, consider when individuals have expected utility represented by the expected mean of the treatment effectiveness net of price. Now consider the canonical case under normal priors over a normally distributed mean when evidence is a sample average of the outcome. This well-known case implies a posterior mean, $z$, which is a weighted average of the prior mean, $z_{0}$, and the evidence $e$ as in

$$
z=(1-w) * z_{0}+w * e
$$

where the weight, $w$, depends the relative precisions of priors and data ${ }^{5}$. This implies that the product is purchased whenever the posterior mean for effectiveness is larger than the price

$$
z \geq p
$$

The more favorable the evidence is (larger $w$ or $e$ ), and the better opinion about the treatment before the evidence (larger $z_{0}$ ), the more likely the purchase. Given a heterogeneous population that differs in their unobservable priors and weights according to the distribution $H\left(z_{0}, w\right)$, the quantity demanded, $D(p, e)$, is the share of the population under $H$ that demands the products under a given observable price and evidence level.

Demand, together with supply, generates an equilibrium price, denoted $P$, and the corresponding equilibrium quantity, $Y=D(p, e)$. These in turn generate aggregate equilibrium spending and health outcomes according to

$$
\begin{aligned}
& S=Y^{*} P \\
& Q=Y^{*} q
\end{aligned}
$$

Now consider an effectiveness study that generates the evidence $e^{\prime}$ thereby replacing the evidence prior to the study e. Generally, we will denote primed quantities as post-CER levels and unprimed as pre-CER levels. If the evidence is more favorable than prior to the study, $e^{\prime} \geq e$, then the posterior is $z^{\prime}=(1-w)^{*} z+$ $w^{*} e^{\prime}$ and demand rises. We will throughout be concerned with only the normal case when an increase in demand raises the equilibrium price and quantity, $Y^{\prime} \geq Y$ and $P^{\prime} \geq P$, an implication consistent with many standard models of different market structures on the supply side ${ }^{6}$. A special case of this would be

\footnotetext{
${ }^{5}$ Specifically, under normal prior normal data likelihood conjugacy, $w=\left(\tau^{2}\right) /\left(\tau^{2}+s^{2} / n\right)$, where $\tau^{2}$ is the prior uncertainty about the mean effect, $s^{2}$ is the standard deviation of effect in the data (evidence) and $n$ is the sample size for the data.

${ }^{6}$ Under a monopoly the price is determined by $P=\operatorname{argmax} D(p, e)^{*} p-C(D(p, e))$ where $C$ is the cost function and under competitive conditions is determined by $D(P, e)=S(P)$ where $S(P)$ is the supply function. In these extreme cases and other intermediate cases, we will assume an outward shift in demand always raises price weakly. For
} 
constant returns and competitive supply when there would be no equilibrium price effects: $P^{\prime}=P$. Now consider when the evidence is valid in the sense that evidence in favor of the status quo is consistent with true quality being higher: $e^{\prime} \geq e$ if and only if $q \geq \mathrm{e}$. This directly implies that both spending and health increases with the new evidence if it is more favorable than before the study: $e^{\prime} \geq e$ if and only if $S^{\prime} \geq S \& Q^{\prime} \geq Q$. To summarize, if evidence is interpreted as an observable signal of the unobservable true quality of a product, changes in evidence have many of the same implications for price and spending as standard shifts in demand induced by quality changes.

\subsection{Comparative Effectiveness, Spending, and Health Outcomes}

Now consider two treatments with true qualities or effectiveness levels, $q=\left(q_{1}, q_{2}\right)$. For example, these two treatments may be first and second generation treatments for a given clinical condition. The evidence generated by CER is now represented by the two scalars, $e=\left(e_{1}, e_{2}\right)$. The demand for the two treatments as a function of prices and evidence on both products are $D_{1}(p, e)$ and $D_{2}(p, e)$. Given the implicit focus of CER on substitutable treatments, we assume that the products are substitutes in both prices and evidence. In other words, demand for a given treatment falls on its own price and the evidence of the other treatment, but rises with the price of the other treatments and its own evidence.

As an example, consider the analogous case to the example of net expected benefits under normality as discussed for the single product case. If two mutually exclusive treatments are considered, then the first is demanded whenever its expected net benefit is larger than that for the second

$$
\left(1-w_{1}\right) * z_{1}+w_{1}^{*} e_{1}-p_{1} \geq\left(1-w_{2}\right) * z_{2}+w_{2}^{*} e_{2}-p_{2}
$$

The relative strength of the evidence, compared to the relative prices, determines the demand for the two products. Similar to before, given a distribution of the vector of unobservable priors and weights $(z$, $w)$, the demands, $D_{1}(p, e)$ and $D_{2}(p, e)$, of the two treatments are functions of the observable prices and evidence.

The infusion of CER evidence into the market may affect equilibrium quantities and prices denoted $Y=$ $\left(Y_{1}, Y_{2}\right)$ and $P=\left(P_{1}, P_{2}\right)$, which in turn determine aggregate equilibrium spending and health according to

$$
\begin{aligned}
& S=S_{1}+S_{2} \\
& Q=Q_{1}+Q_{2} .
\end{aligned}
$$

Without loss of generality, we assume that the first (second) treatment is the winner (loser) of the CER in the sense that quality evidence is improved (worsened) by the CER 


$$
e_{1}^{\prime} \geq e_{1} \& e_{2}^{\prime} \leq e_{2}
$$

Holding prices constant, the CER causes the demand for the first (second) product to rise (fall);

$$
D_{1}\left(p, e^{\prime}\right) \geq D_{1}(p, e) \quad \& \quad D_{2}\left(p, e^{\prime}\right) \leq D_{2}(p, e)
$$

This occurs because the two treatments are substitutes in evidence in the sense discussed above.

Now consider the standard case ${ }^{7}$ when the rise (fall) in demand of the first product implies a weakly higher (lower) price and quantity as in

$$
P_{1}^{\prime} \geq P_{1} \quad \& \quad P_{2}^{\prime} \leq P_{2} \text { and } Y_{1}^{\prime} \geq Y_{1} \quad \& \quad Y_{2}^{\prime} \leq Y_{2}
$$

Figure 1 depicts this impact of CER under the simple case of a competitive supply, although the implied effects carry over to many heterogeneous standard non-competitive market structures. For illustrative purposes only, the Figure concerns the case when demand and supply curves for both treatments coincided prior to the CER.

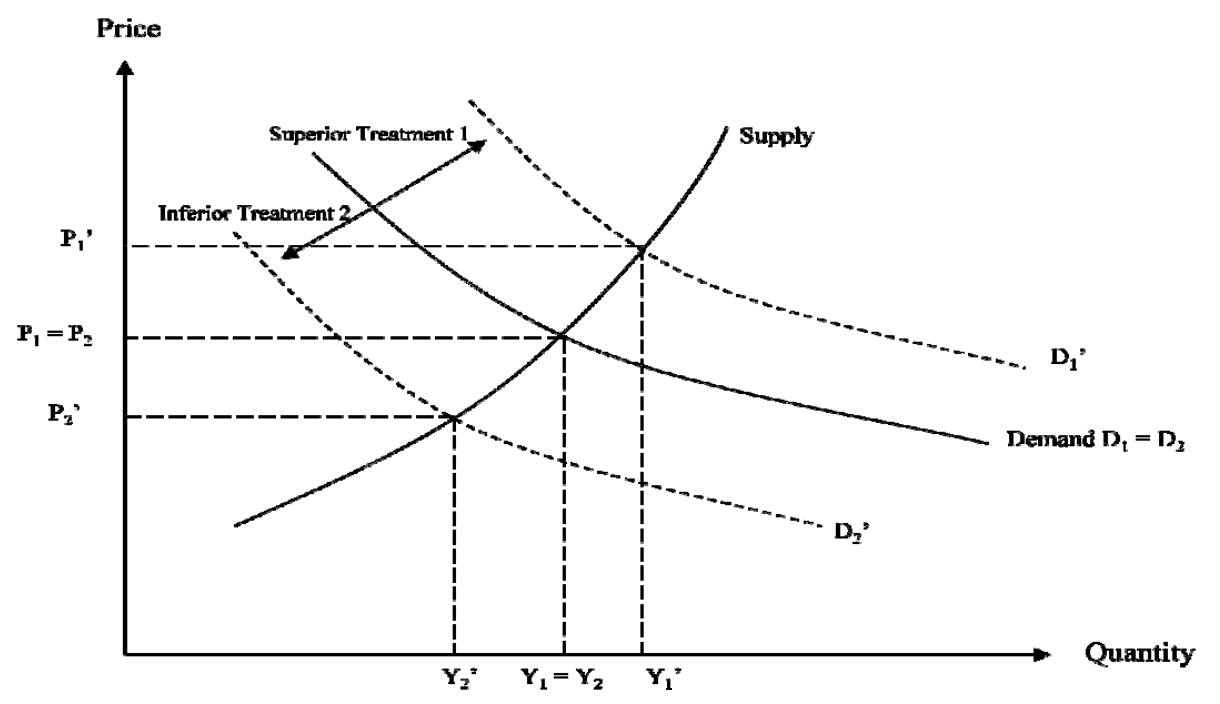

Figure 1: Demand shifts associated with CER

An outward (inward) shift in demand for the winner (loser) of the CER raises (lowers) both the equilibrium quantity and price of the product.

The health and spending implications of these market responses to CER can be traced out from this. As both quantity and price rise for the first treatment, it follows directly that sales or spending on it

\footnotetext{
${ }^{7}$ To show this under competitive markets for gross substitutes, assume not. In that case, $P_{1}$ is lowered and $P_{2}$ is raised. Then the equilibrium quantity must fall for the first good and rise for the second as the quantity supplied does. However, in order for the quantity demanded of the first good to fall even though its demand shifts out and its price falls, it must be that the price of the second good falls--a contradiction.
} 
rises; $S_{1}{ }^{\prime} \geq S_{1}$. By an analog argument, the spending on the second treatment will fall; $S_{2}{ }^{\prime} \leq S_{2}$. The impact on overall spending $S^{\prime}-S$ is thus indeterminate as overall spending may rise or fall, depending on whether the increase in sales of the winner dominates the fall in sales of the loser. However, the aggregate health effect is clearly positive, $Q^{\prime} \geq Q$, as long as the evidence of the CER is valid in the sense that the winner of the CER is indeed of higher quality: $e_{1}^{\prime} \geq e_{1}$ and $e_{2}^{\prime} \leq e_{2}$ if and only if $q_{1} \geq q_{2}$. This is because quantity is increased for the winner of the CER at the expense of the loser ${ }^{8}$. Thus, if the intended overall effects of CER are lower spending and higher health, the effect on spending is inconsistent with that intention while the second effect on health is consistent.

\section{Section 3: Impact of CER in a Subsidized Market}

In most countries, health care markets are subsidized, thereby separating supply-prices received by sellers and demand-prices paid by patients. For example, the US government, through the Medicare and Medicaid programs, pays manufacturers and providers at prices above the co-pays of enrollees. In a subsidized market, CER will impact health and spending not only through the basic demand shifts discussed earlier but also through any changes in subsidy levels due to the CER. For example, Medicare or Medicaid may favor winners of CER studies through lower co-pays, reduced prior authorization, or higher reimbursement rates to manufacturers ${ }^{9}$.

For a given subsidy level $s$, let the equilibrium quantity, supply and demand prices for a treatment be denoted by $Y(s), P^{\mathrm{S}}(s), P^{\mathrm{D}}(s)$ where $P^{\mathrm{s}}(s)=P^{\mathrm{D}}(s)+s$ and $Y(s)=D\left(P^{\mathrm{D}}(s), e\right)=S\left(P^{\mathrm{S}}(s)\right)$. It is well known that increasing the subsidy raises the supply price, lowers the demand price, and raises the equilibrium quantity: $\mathrm{d} P^{\mathrm{S}} / \mathrm{d} s \geq 0, \mathrm{~d} P^{\mathrm{D}} / \mathrm{d} s \leq 0, \mathrm{~d} Y / \mathrm{d} s \geq 0$.

Consider now $s=\left(s_{1}, s_{2}\right)$ as the subsidy levels for the two treatments and when CER leads governments to subsidize the winner more at the expense of the loser

$$
s_{1}^{\prime} \geq s_{1} \quad \& \quad s_{2}^{\prime} \leq s_{2}
$$

Now consider the price and quantity effects of when a CER study not only raises demand as before, but also changes subsidy levels to favor winners over losers. Thus, for the winner of the CER, not only does the demand shifts outward as before, but the subsidy also rises. This is a principal rationale for valuebased insurance designs: reduce financial barriers (such as co-pays) for the patients so that they are induced to use treatments that provide value (Fendrick et al., 2001). Likewise, for the loser of the CER, not only does the demand shift inward as before, but the subsidy also falls.

\footnotetext{
${ }^{8}$ If there are more than two mutually exclusive treatments, then market expansion effects would require stronger substitution assumptions.

${ }^{9}$ The current CER efforts in ARRA (2009) does not regulate payer responses to CER evidence.
} 


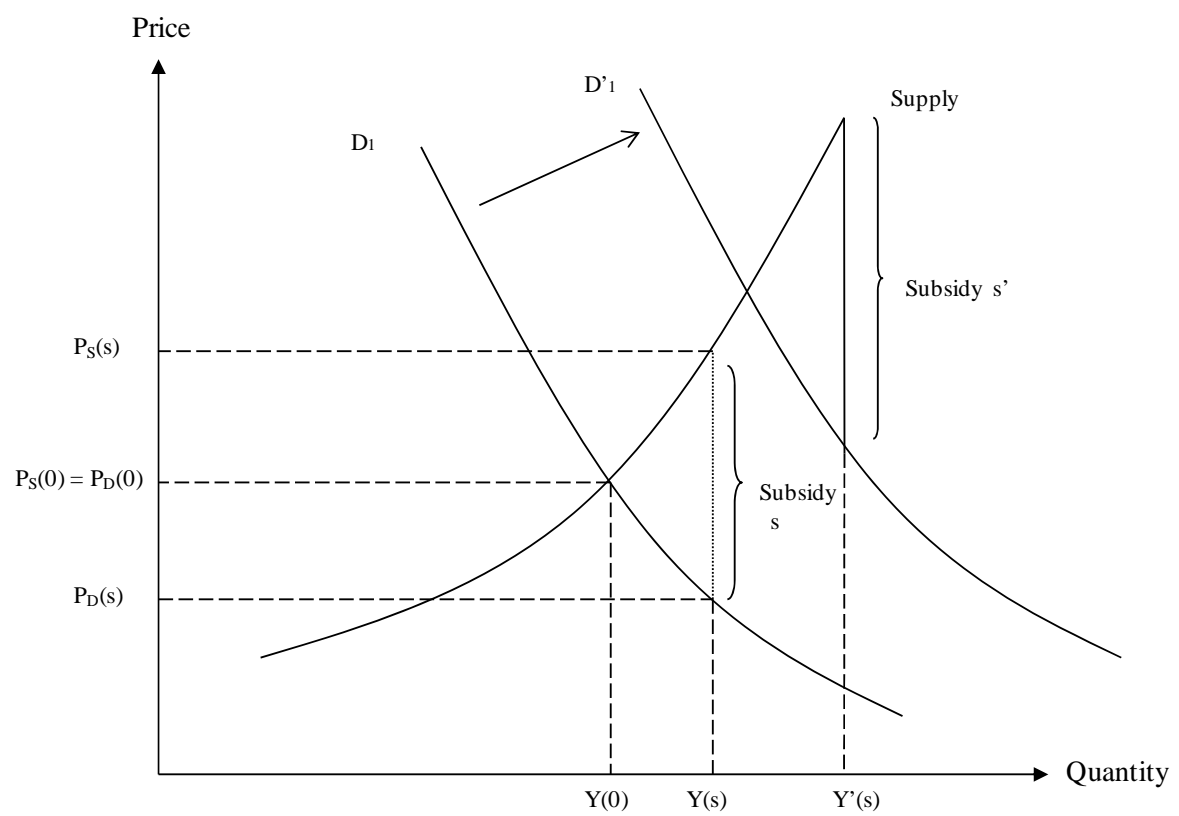

Figure 2: Multiplier Effects of CER under Responsive Subsidies

Figure 2 shows the demand and subsidy expansion of a winner of a CER. It follows that a responsive subsidy policy has a reinforcing "multiplier effect" on prices and quantities compared to the private market effects when demand responds without coverage changes. More precisely, under common models of the supply side ${ }^{10}$, the effect on the quantity and supply price of the first good, $Y_{1}{ }^{\prime}-Y_{1}$ and $P^{S}{ }_{1}$, - $P_{1}^{S}$, will be larger when subsidies, in addition to demand, respond to the CER. Likewise, the fall in the quantity and supply price of the second good, $Y_{2}-Y_{2}^{\prime}$ and $P_{2^{-}}^{S} P^{S}{ }_{2}{ }^{\prime}$, will be larger with an incremental subsidy response as well.

The aggregate spending in a subsidized market is determined by the total spending by both patients and the government so that quantities are priced out at supply prices, $S=S_{1}+S_{2}$ where $S_{\mathrm{k}}=Y_{\mathrm{k}}{ }^{*} P_{\mathrm{k}}^{S}$. The aggregate health $Q=Q_{1}+Q_{2}$ is determined as before. With the price and quantity responses discussed above, the impact of spending $S^{\prime}$ - $S$ will still be indeterminate as before. The spending on the CER winner rises more than before but the spending on the loser falls more than before. The impact on health, $Q^{\prime}-Q$, will be larger when subsidies respond as more substitution will take place towards the higher quality treatment. However, the cost-effectiveness of technology as it is used in response to this subsidy may be very different (and potentially worse) than the cost-effectiveness ratio that had been used to determine the level of subsidy in the first place.

\footnotetext{
${ }^{10}$ For example, this will be the case under competitive supply conditions when the supply prices satisfy $S_{\mathrm{k}}\left(P_{\mathrm{k}}^{\mathrm{S}}\right)=D_{\mathrm{k}}\left(P^{\mathrm{S}}-s, e\right), \mathrm{k}=1,2$.
} 
This positive analysis of the effects of subsidy responses on spending and health do not consider the equally important normative issues of optimal subsidy design. For example, if there is some inefficient matching in the first place a valid CER may well improve welfare under optimal subsidies but the payer responses compounding the private responses may indeed go too far. More generally, our positive analysisof spending and health do not conflict with the normative principals of value-based insurance designs (Chernew et al., 2007; Goldman and Philipson, 2007, Pauly and Blavin, 2008).

\section{Section 4: Impact of CER under Heterogeneous Treatment Effects}

This section extends the previous analysis of health- and spending impacts of CER by considering heterogeneity in treatment effects or quality across patients. As opposed to the previous sections, a responsive subsidy policy may adversely affect health outcomes under heterogeneous treatment effects. Consider the case when there is a joint distribution $F\left(q_{1}, q_{2}\right)$ of true effectiveness or qualities across patients in the population. This is illustrated in Figure 3.

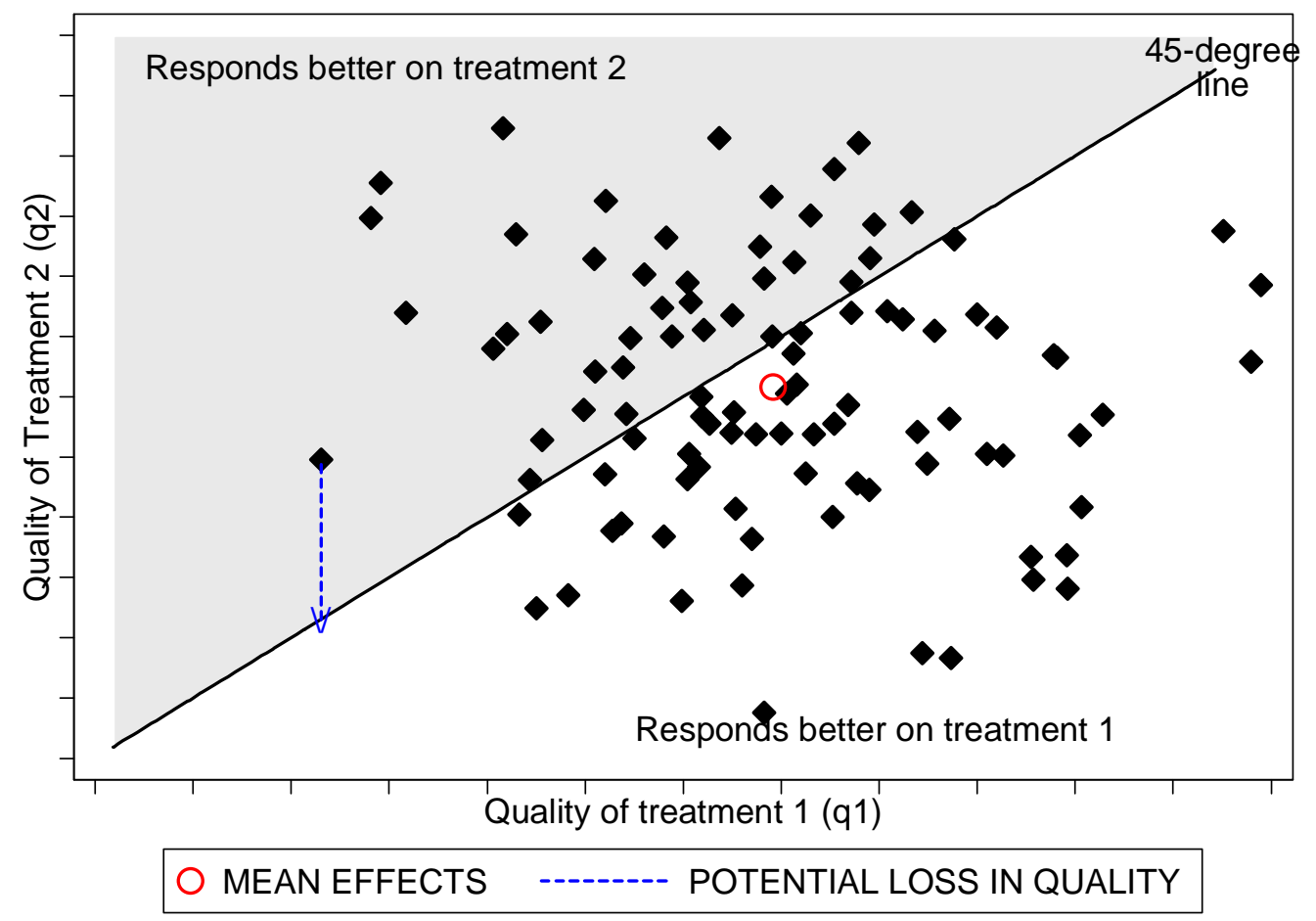

Figure 3: Distribution of Treatment Responses

A given point in the figure corresponds to the two qualities, $q$, for a given patient and the distribution of points in the Figure corresponds to the distribution $F$ across all treatment effects. The patients below 
(above) the 45-degree line are those benefitting more from the first (second) treatment, thereby making up the two groups above. As revealed in the Figure, the first treatment is the winner, say due to that it had a larger mean treatment effect than the second treatment. Consider when a responsive subsidy policy favors the first treatment. Specifically consider if it had a higher mean or median treatment effect than the second treatment in the CER study and that this resulted in substitution towards the first treatment by all groups. This may imply that health is adversely affected for those in the group above the 45 degree line. However, the overall population impact will depend on the degree of self-selection that existed before the subsidy. That is, how many of the patients, both above and below the 45 degree line, actually chose the second treatment before the subsidy. This notion is formalized below.

Conditional on a given set of true effects $q=\left(q_{1}, q_{2}\right)$, demand is a function of price and evidence as before and represented by $D_{1}(p, e \mid q)$ and $D_{2}(p, e \mid q)$. Aggregate health outcomes of the population is determined by the conditional demand functions aggregated up over all true quality levels. For example, the aggregate health outcome for patients taking the second treatment is given by:

$$
Q_{2}=\mathrm{W} \iint D_{2}(p, e / q) q_{2} \mathrm{dF}\left(\mathrm{q} \mid q_{1} \geq \mathrm{q}_{2}\right)+(1-\mathrm{W}) \iint D_{2}(p, e / q) q_{2} \mathrm{dF}\left(\mathrm{q} \mid q_{1}<\mathrm{q}_{2}\right)
$$

where $W$ is the fraction of patients for whom the first treatment is of higher effectiveness. The aggregate health outcome in the population is given by $Q=Q_{1}+Q_{2}$. The impact of CER on aggregate health outcome depends on how the CER leads patients on the two treatments to move towards their most- or least effective treatment. In the expression above for the health associated with the second treatment, the first term represents patients who would benefit from moving to the first treatment and the second term patients who would not.

Now consider a subsidy response for a public subsidy program for a poor population such as e.g. Medicaid in the US. In particular, consider when the CER that raises the demand price for the loser of the CER, the second treatment, beyond the reach of the patient population. Consequently, aggregate demands for the two treatment $D_{1}^{\prime}=D_{1}+D_{2}$ and $D_{2}^{\prime}=0$ respectively due to that all patients of the loser of the CER switch to the winner. Thus, the effect of CER on total aggregate health is driven by patients who change their treatment choice from the second to the first treatment in response to the subsidy change induced by the CER. For those who were on the loser of CER prior to the subsidy response, the impact on health will be negative for those whom the loser of the CER was most effective, $q_{2} \geq q_{1}$, but positive for the those for whom the winner of the CER was $q_{1} \geq q_{2}$. More generally, a responsive subsidy lowers the price of most effective care for people who should be treated by the winner of the CER. However, it also raises the price of most effective care for people who should be on the loser of the CER. The relative magnitude of these two effects determines the overall health effects.

The basic issue is that two aspects drive overall health outcomes when coverage is responsive to the aggregate CER evidence. The first is heterogeneous treatment effects and that price responses lead 
patients to switch away from their best treatment compared to those who switch towards their best treatment. The issue is that the evidence from CER is used to form product-specific coverage policies. This is a problem when treatment effects are patient-specific. Heterogeneity is necessary but not sufficient for this to occur; what is needed is that the joint distribution of treatment effects, $F$, has a support that spans both sides of the 45-degree line as illustrated in the Figure 3 so that that both groups are occupied; $\operatorname{Pr}\left(q_{1} \geq q_{2}\right) * \operatorname{Pr}\left(q_{1}<q_{2}\right)>0$.

\section{Section 5: Empirical Analysis of Responsive Subsidies for Antipsychotics}

In this section, we conduct an illustrative empirical analysis of the potential impact of CER responsive subsidies using the case of antipsychotic drugs. These drugs represent one of the largest drug classes in Medicaid, one of the major US public subsidy programs (Bruen and Ghosh, 2004).

We find that if Medicaid coverage policy had responded to the CER results of CATIE by providing partial coverage that only reimburses for first generation drugs and risperidone (one of the second generation drugs), then compared to the pre-CER policy of covering all drugs, it would save about $40 \%$ of $\$ 2 B$ class spending over one and half years. However, taking into account the observed heterogeneity in treatment effects, limiting access to all but one second generation drug would incur a net loss valued at about $25 \%$ of class spending. Thus, for one the largest drug classes in one of the major health care subsidy programs, heterogeneity alters not only the magnitude but also the sign of the effect on outcomes due to reimbursement responses to CER studies.

\subsection{Interpreting the CATIE Trial CER in our Framework}

Antipsychotic drugs represent the primary treatment for patients with schizophrenia. Beginning in 1990, a second generation of antipsychotic drugs, also known as atypical antipsychotics (AA), was introduced. These drugs are believed to cause less movement disorders as side effects compared to the first generation antipsychotics (also known as "typicals" or neuroleptics) (Kane, 2004; Meltzer 2009). More recently, some of the second generation antipsychotics have been linked to increased metabolic side-effects such as weight gain and diabetes (Meltzer, 2005).

Following a series of many small comparative effectiveness studies conducted on this issue (Polsky et al., 2006; Leucht et al., 2009), a large pragmatic comparative effectiveness trial, called CATIE, was conducted for antipsychotics in the US (Lieberman et al, 2005). The CATIE results found equivalence in the effectiveness for a first generation antipsychotic drug (typical or FGA) and all second generation antipsychotics (atypicals or SGAs) drugs (Lieberman et al, 2005; Rosenheck et al, 2006). Based on these results, many argued that Medicaid should preferentially subsidize FGAs over SGAs (Banthin and Miller, 
2006; Rosenheck et al., 2007; NY Times, 2005; Soumerai and Law, 2007). Subsequent to the release of CATIE, approximately $40 \%$ of the state-run Medicaid programs have instituted prior authorization restrictions on some SGAs (Polinski et al, 2007). Little is known about the quantitative health and spending effects of such coverage proposals and policies. To better understand such effects, we simulate the impact on health and spending for the counter-factual case of providing only partial coverage or no coverage for SGAs ${ }^{11}$.

In our framework, we interpret the CATIE trial as a typical CER and then consider the health and spending implications of subsidies, within Medicaid, responding to the evidence generated by this CER study. More precisely, we let the FGAs be treatment 1 and the SGAs represent treatment 2 according to our earlier notations. In other words, our analysis is set up such that the FGAs are the winner of the CER and the SGAs are the losers of the CER. We will assume, given the poverty of the patient population, that without subsidies there would be no demand for these therapies: $D_{1}(c, e)=D_{2}(c, e)=0$. Thus, in this particular case, the private demand and price-effects are nullified as all utilization is determined by subsidy policy. Therefore, any viable Medicaid market would need to have supply prices $P^{\mathrm{S}}$ (provider reimbursement) at or above costs, denoted $Z$, but demand prices $P^{\mathrm{D}}$ (patient co-pays) at or below costs. i.e, $P^{S} \geq Z \geq P^{\mathrm{D}}=P^{\mathrm{S}}-s$, where $s$ is the subsidy.

Given such subsidy levels for both treatments before the CER, consider if a Medicaid program were to respond to the evidence of the CER by only covering the FGAs (winner) but not the SGAs (loser) of the CER represented by CATIE. This would entail that the condition above was satisfied for the winner but not the loser after the CER, thereby raising demand prices for the SGAs relative to the FGAs and eliminating the market for the SGAs but expanding the market for the FGAs

$$
D_{1}^{\prime}=D_{1}+D_{2} \& D_{2}^{\prime}=0 \text {, implying } 0=Y_{2}^{\prime}<Y_{2} \quad \& \quad Y_{1}^{\prime}>Y_{1} \text {. }
$$

Such an effect due to responsive subsidies from a traditional CER may lead to adverse health effects on the aggregate due to heterogeneity in treatment effects in this population. Specifically, under pre-CER subsidies, patients and their physicians are at liberty to switch drugs with ease so that they can identify and settle on the drug that gives the most benefit. However, due to third-party reimbursement under risk-sharing the relative costs and benefits facing patients and physicians or providers may not correspond to the true ones. Patients for whom $q_{1}>q_{2}$ are more likely to identify and continue taking FGAs and vice versa for those patients where $q_{1}>q_{2}$. With CER responsive subsidy however, a shift in the distribution of uses happen: patients who were receiving SGAs $\left(q_{2}>q_{1}\right)$ will be forced to take FGAs, thereby diminishing their health. Thus the overall effect on aggregate health, $\Delta Q$, would be driven by the the impact on those who were consuming SGAs before the subsidy policy but forced to take a FGA under the altered subsidy policy. Note that under the pre-CER policy, patients can have repeated trials

\footnotetext{
${ }^{11}$ This no-coverage reimbursement response is inconsistent with current law and therefore the partial coverage scenario is our primary counterfactual policy. However, we include the no-coverage scenario to understand the desirability of future policies and laws that may potentially alter those currently in place.
} 
of all medication options. Thus, patients who truly preferred the FGAs to SGAs, $q_{1}>q_{2}$, would eventually have been induced to take FGAs under pre-CER policy and therefore a CER-responsive exclusive subsidy for the FGAs cannot induce increases in health for this cohort. Thus $\Delta Q$ is most likely negative.

In the analysis below we calculate the average health outcome effects for the entire Medicaid population under alternative access policies. The differences between these scenarios will be based on the sub-group of Medicaid patients for whom an atypical was the best therapy.

\subsection{Policy scenarios}

The first policy is the Pre-CATIE scenario that assumes status quo coverage and allows full reimbursement for both generations of antipsychotic drugs. Since the second-generation drugs are more costly, this resembles a greater subsidy on the second generation drugs compared to first generation drugs (i.e. $s_{2} \geq s_{1}$ ). Under this policy, the demand for these drugs are partly determined by the demand prices faced by the patients, which are close to zero $\left(P_{D}(s)=0\right)$, so that overall spending closely coincides with the supply prices, $\mathrm{P}_{\mathrm{S}}$, and is mostly incurred by Medicaid. ${ }^{12}$ Demand is also affected by heterogeneity in treatment effects: with unrestricted coverage physicians are able to try out alternative drugs and settle on a drug that appears to produce better quality for an individual patient. To simulate the effects of CER-responsive subsidy policies, we compare the pre-CATIE scenario with two hypothetical (counter-factual) post- CER scenarios - the Partial Coverage policy and the No Coverage policy.

Under the Partial Coverage scenario, only risperidone (an SGA) is covered along with FGA, thereby allowing equilibrium quantity demanded for SGAs, $Y_{2}{ }^{\prime}$, to be positive. All other second generation drugs are not included in the formulary, and therefore are not covered. We consider risperidone to be the only atypical reimbursed under the Partial Coverage policy as it is the only generic SGA available in the market and consistently finds itself on the top tier of preferred drug lists across most Medicaid programs.

Under the No Coverage policy the responsive subsidy policy entails that none of the second generation drugs are covered: $s_{2}^{\prime}=0$. Given the low income of the Medicaid population, this is assumed to eliminate demand in this population so that the post-CER quantity satisfies $Y_{2}^{\prime}=0$. This case is included not because of its likelihood of being adopted but to trace out the implications of the common policy

\footnotetext{
12 Total Medicaid expenditures on antipsychotic medication increased from $\$ 484$ million in 1995 to $\$ 1.3$ billion in 1998 (Lewin Group, 2000). In 2004, the annual health care costs for patients with schizophrenia is estimated to be about US $\$ 28$ billion, of which nearly one-third can be attributed to pharmacy costs (Gilmer et al., 2004). More recent estimates suggest that expenditures on antipsychotic medications across all payers have crossed $\$ 10$ billion this year and account for a third to a half of all mental health expenditures (NIMH, 2006).
} 
prescription that only the most cost-effective care reimbursed. When care that is not cost-effective is not reimbursed, poor individuals cannot access it and this has important health effects under heterogeneity.

\subsection{Methods}

We evaluate each policy described above over an 18-month period, corresponding to the length of the CATIE trial. We focus on three second-generation antipsychotic drugs (risperidone, olanzapine, quetiapine), as well as one first generation drug, perphenazine. These comprise nearly $70 \%$ of the market of antipsychotic prescriptions written in the United States. Wu et al. (2006) estimated prevalence of diagnosed schizophrenia among non-elderly Medicaid patients to be $1.66 \%$. We apply this estimate to the 15 million non-elderly adult Medicaid enrollees (www.statehealthfacts.org) to obtain a total number of 250,000 non-elderly adult enrollees with schizophrenia who are affected by alternative policies.

Total costs under each policy is calculated based on monthly costs estimates from CATIE data and those reported by Rosenheck et al (2006).

We first calculate the baseline QALY level where the pre-treatment (baseline) quality of life weight for this population $\left(=0.68\right.$ ) persists throughout the 18 -month period (i.e. $0.68^{*} 1.5=1.02$ QALY per patient). This is the same under each of the counterfactual policy scenarios. Next we model the deviations in quality of life over the same time window under alternative policies and add the additional QALYS gained or lost to the baseline level. These additional gains or losses in QALYs are calculated using an area-under-the-curve approach based on the time trajectory of quality of life weights. Specifically, we approximate this area with a triangle whose slope is determined by the rate of change in QOL weight over time under each scenario. We now describe the calculations for costs and benefits under each policy in more details.

\section{3.a. Pre-CATIE scenario}

Under this policy, irrespective of the drug that a patient initiates on, the physician can switch patients as needed to an alternative drug that may be more efficacious for that patient. We capture the overall effect of these switches using the intention-to-treat rate of change in QOL over time for specific drug initiations from CATIE data (shown in Figure 4 and summarized in Table A1). ${ }^{13}$

\footnotetext{
${ }^{13}$ These intention-to-treat effects represent the average quality levels for a given initial drug assignments after incorporating the effect of trial-and-error selection into the best treatment. We apply mixed effects linear models to individual-level longitudinal quality of life data from CATIE and estimate the intention-to-treat effects of the
} 
We assume that the drug-specific shares of prescriptions estimated from the 2005 IMS data represent equilibrium shares of use both across patients at the initial assignment and within each initial assignment over a one year period. Therefore, we use these shares to split the 250,000 patients with schizophrenia to obtain the number of patients initiating with each of these drug. The Pre-CATIE scenario is now shown in Figure 4.

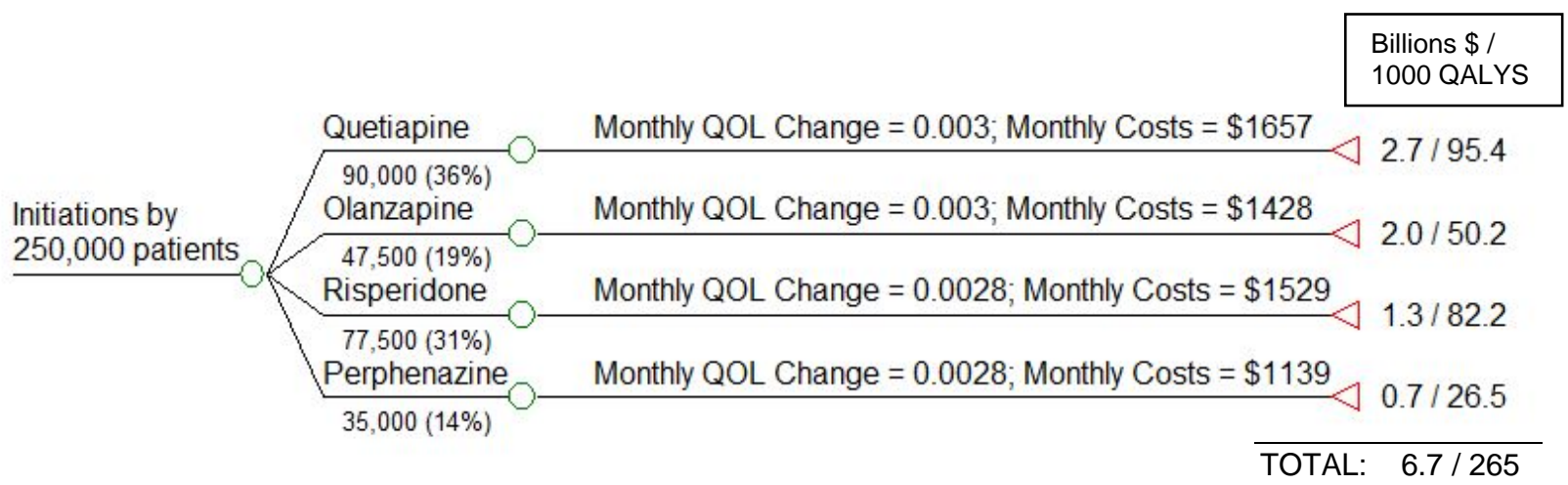

Figure 4: Patterns of utilization and outcomes under the Pre-CATIE policy. Final payoffs are shows as $\$$ Billions / 1000 QALYS. Pre-CATIE scenario.

The total health effect, $E_{k}$, generated from a drug initiation is calculated by multiplying the number of patients initiated on this drug with the sum of 1 ) the baseline QALYS = 1.02 QALYs per patient, and 2) the area under the curve representing deviations in QALYs from baseline $=0.5 *$ (intention-to-treat monthly rate of change in $\left.\mathrm{QOL}^{*} 18\right) * 1.5$ years. For example, the 90,000 patients initiated on quetiapine are expected to experience $90,000 \times(1.02+(0.5 \times(0.003 * 18) \times 1.5))=95,445$ QALYS . Similar calculations are made for each drug initiation and then the total benefits are summed across all the drug initiations. Total costs under this policy are calculated by multiplying the number of patients initiated on a drug with the corresponding intention-to-treat monthly costs estimates (Figure 4 and summarized in Table A1) of total drugs and services costs, as reported by Rosenheck et al (2005) in their Supplemental Table C (reproduced here in Table A1), and summing over 18 months. Of these costs, about 18 - $34 \%$ is due to the use of the antipsychotic medications (Table A1), the remainder being utilization of psychiatric services.

\section{3.b. Partial Coverage Scenario}

initial assignment of alternative drugs. Specifically, we look at the coefficients on treatment-time interaction to compare the average rate of change in $\mathrm{QOL}$ weight under alterative first line treatment. 
The Partial Coverage scenario is illustrated in Figure 5. We assume that all patients who had chosen a SGA to initiate their treatment under the pre-CER policy would now choose to initiate treatment with risperidone as it is the only atypical covered.

Among patients who initiate with risperidone, $26 \%$ (estimated using CATIE data) find risperidone to be efficacious and tolerable and continue on it. The remaining 74\% discontinue risperidone after 5 months (median time to discontinuation estimated using CATIE data). Patients initiating with perphenazine follow the same route as above, with $25 \%$ of the patients staying on the drug for the full year and $75 \%$ discontinuing after 6 months. Discontinuers of either perphenazine or risperidone can switch to the alternative and prevent relapse. Since we do not directly have an estimate for the magnitude of such an effect from the CATIE data, we will assume that the relapse rate among discontinuers from either arm is $5 \%$, a reduction from our $11 \%$ estimate for when no switching is possible (see No Coverage scenario).

We run separate mixed effects models to estimate the effect of the initially assigned drug on monthly rate of changes in quality of life. For those who continue on their initial assignment, we summed over the duration of the trial, and only until the time of discontinuation for those who discontinued the initially assigned drug. These estimates are shown in Figure 5 and also summarized in Table A2 in the Appendix.

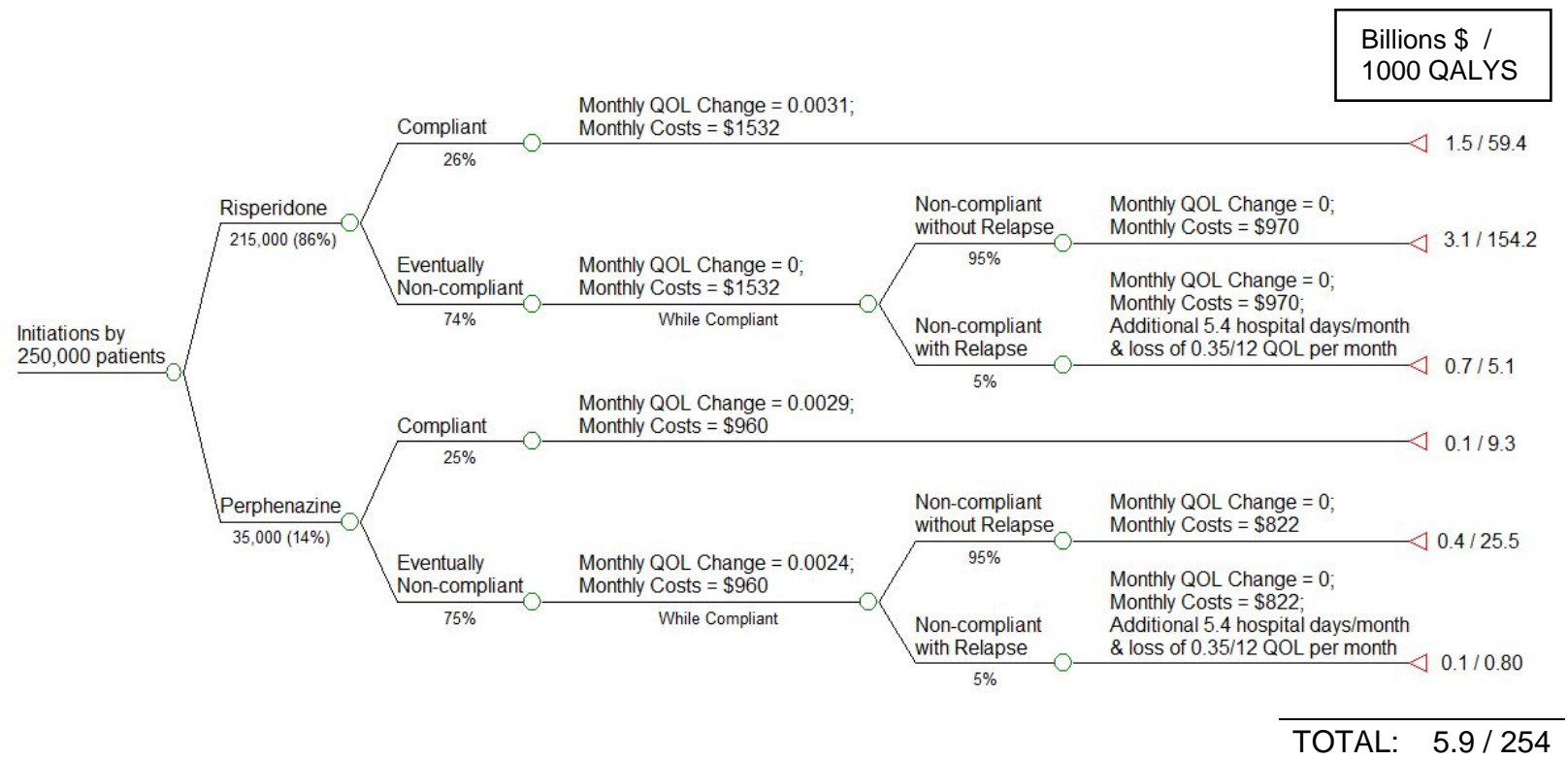

Figure 5: Patterns of utilization and outcomes under the Partial Coverage with a responsive subsidy policy. Final payoffs are shows as \$ Billions / 1000 QALYS. 
For continuers, we apply the same method as under the pre-CER policy, where total QALYs are calculated by multiplying the number of continuers with the sum of the baseline QALY and the area under the curve for deviations from baseline QALYs based on drug -specific monthly rate of change in QOL (as indicated in Figure 5 and summarized in Table A2).

For discontinuers who do not relapse, the deviations from baseline QALYs are calculated only up to the month where discontinuation occurs. Thereafter, baseline QALYs are assumed to persist (this allows us to obtain a conservative estimate for the adverse effects on health since no further deterioration is accounted for). Patients who relapse after discontinuation, on average, spend 5.4 additional days per month (valued at $\$ 1000 /$ day) in psychiatric hospitals ${ }^{14}$ (Ascher-Svanum et al., 2010) and experience a loss in quality of life of $0.35 / 12$ per patient per month over the remaining duration of the 18-month period (Lenert et al. 2004). ${ }^{15}$

Costs for the compliant groups under each drug initiation are calculated based on the estimates of total drugs and services reported by Rosenheck et al (2005) in their Supplemental Table D, where treatment crossovers were excluded. The same monthly costs are applied to the noncompliant group during the month when they were on their initial assignment. After discontinuation, patients continue to accumulate the assignment-specific average monthly service costs (but not any drug costs ${ }^{16}$ ).

Note that compared to the pre-CER scenario, estimates of the $\Delta Q$ for Partial Coverage arise due to the adverse impact on the health of patients who discontinue initial assignments and face limited options of alternative medications to switch to.

\section{3.c. No Coverage Scenario}

The No Coverage scenario is illustrated in Figure 6. We assume that all schizophrenia patients are initiated with perphenazine, $25 \%$ these patients (estimated using CATIE data) find perphenazine to be efficacious and tolerable and therefore continue on it. The remaining $75 \%$ discontinue perphenazine after six months (median time to discontinuation estimated using CATIE data) but are not able to switch

\footnotetext{
${ }^{14}$ Based on Weiden and Olfson (1995) estimate of two hospitalization associated with relapse, we use AscherSvanum et al. 's (2010) RR category to represent the utilizations associated with relapse. Conservatively, we use their comparison of the RR group to that of the NR group (ideally this should have been the NN group, which would mean a bigger difference, but such data were not reported) in terms of psychiatric hospitalizations: 1.46 hospitalizations/year * 51.24 days/admission vs 0.99 hospitalizations/year*9.84 days/admission, which amounts to a difference of 65 hospital days/year of about 5.4 days/month.

${ }^{15}$ The drop is QOL could range from 0.45 to 0.25 based on moving from a mild to extreme or moderate to extreme symptom severity levels. We choose the mid-point as the baseline level for our analyses and conduct a sensitivity analysis with the most conservative value $(0.25)$.

${ }^{16}$ To obtain a conservative estimate on costs, we did not include costs of concomitant medications, as part of these costs may be due to the use of antipsychotics themselves.
} 
to other drugs due to the lack of subsidies, and thus will be without drug therapy for the remaining months (i.e. $Y_{2}^{\prime}=0$ ). Monthly rates of change in QOL under perphenazine initiation are the same as under the Partial Coverage policy. These estimates are shown in Figure 6 and also summarized in Table A2 in the Appendix.

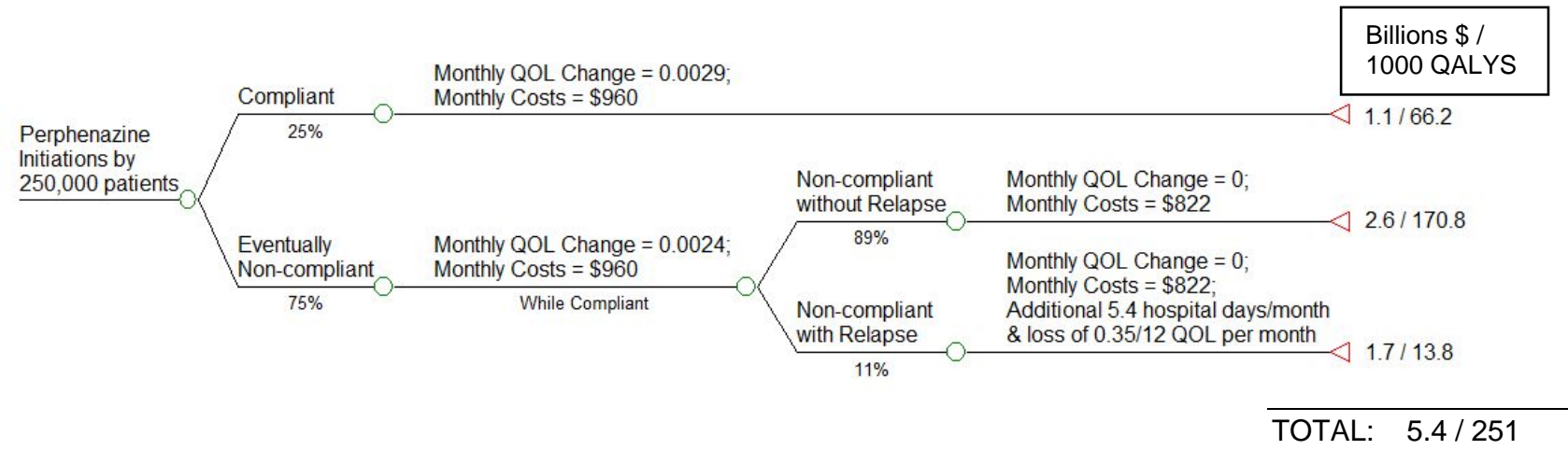

Figure 6: Patterns of utilization and outcomes under the No Coverage with a responsive subsidy policy. Final payoffs are shows as \$ Billions / 1000 QALYS.

Calculation of total QALYs and costs follow identical methods as the perphenazine assignment described under the Partial Coverage policy. However, under the No Coverage policy, $11 \%$ of perphenazine discontinuers relapse (Weiden and Olfson, 1995) and experience the associated costs (described above) and an additional loss of $(0.35 / 12) \mathrm{QOL}$ units per patient per month over the remaining duration of the 18-month period (Lenert et al. 2004).

\subsection{Results}

Under the Pre-CATIE Scenario, the total additional QALYS $(Q)$ over baseline generated across all treatments over a eighteen month period for this population adds to 265,000 QALYs while the total costs adds to $\$ 6.7 \mathrm{~B}$ (Table 1). Under Partial Coverage, patients initiating with risperidone will generate a 218,500 QALYs and those initiating on perphenazine will generate a 35,500 QALYs, totaling to 254,000 QALYs for this scenario at a cost of $\$ 5.9 \mathrm{~B}$. The No Coverage policy, in turn, will produce a total of 251,000 QALYs at total annual costs of $\$ 5.4 B$, mainly due to the severe effect on the quality of life and psychiatric service utilization of those who relapse due to the unavailability of alternate drugs.

Table 1 presents the net monetary benefits (Stinnett and Mullahy, 1998) of alternative policies when each QALY is valued at $\$ 100,000$. Compared to the Pre-CER policy, the Partial Coverage policy is expected to produce a loss in value that is worth $\$ 0.50$ Billion over an 18 month period in this 
population. Based on estimates from the CATIE trial (Table A1), the class spending on antipsychotics by Medicaid for this target population is $\$ 2.0 \mathrm{~B}$ in this time frame. A Partial coverage policy, which most closely resembles the real restrictions put by many Medicaid programs, will generate losses that are worth $25 \%$ of overall class spending. The No Coverage policy on the other hand will produce a loss of $\$ 0.10 \mathrm{~B}$ ( $5 \%$ of class spending) over Pre-CER policy for Medicaid programs over this period. This loss includes the loss of about 14,000 QALYs, which is worth $\$ 1.4 B$ and that represents a $5 \% \quad(=16,000$ / $265,000)$ reduction in overall health for this already vulnerable population.

Table 1: Net Monetary Benefits (NMB) at $\mathbf{\$ 1 0 0 , 0 0 0 / Q A L Y ~ f o r ~ C E R - r e s p o n s i v e ~ p o l i c i e s ~ f o r ~} \mathbf{2 5 0 , 0 0 0}$ nonelderly adult patients with schizophrenia under Medicaid

\begin{tabular}{lccllc}
\hline & QALYS & QALYS (in \$B) & COSTS (in \$B) & NMB $(\$ B)$ & Incr. NMB (\$B) \\
\hline Pre-CER & 265,000 & 26.5 & 6.7 & 19.80 & \\
Partial Coverage & 254,000 & 25.4 & 5.9 & 19.30 & -0.50 (vs Pre-CER) \\
No Coverage & 251,000 & 25.1 & 5.4 & 19.70 & 0.40 (vs Partial) \\
\hline
\end{tabular}

Notes: Partial Coverage: Access only to first generation perphenazine and second generation risperidone.

No Coverage: The most stringent policy with access only to first generation perphenazine $N M B=$ QALYS (in \$B) - COSTS

Sensitivity analysis with the QOL effect of relapse reveals that even if we assume the most conservative effect of relapse on QOL (i.e. loss of 0.25/12 QOL per month per patient), it would generate 255,000 QALYs under Partial coverage and 253,000 QALYs under No coverage scenarios. This would translate to a net loss of $\$ 0.20 \mathrm{~B}$ under Partial coverage policy and a net gain of $\$ 0.10 \mathrm{~B}$ under No coverage policy compared to the Pre-Coverage scenario.

\section{Section 6: Concluding Remarks and Future Avenues of Research}

Given the growth in public subsidization of CER to improve health and lower cost, little conceptual and empirical understanding exists concerning the quantitative impact of CER. This paper analyzed the impact of CER on patient health and costs interpreting CER as a shifter of demand to some treatments at the expense of others. We traced out the general spending and health implications of such shifts in private- as well as subsidized health care markets. In contrast to commonly held views, our analysis implied that product specific CER may increase spending and adversely impact health under plausible assumptions of how markets respond to the infusion of new quality information. This was particularly relevant when treatment effects are heterogeneous as product specific coverage policies failed to account for patient-specific treatment effects. We illustrated these economic effects for antipsychotics that are among the largest drug classes of the US Medicaid program and for which CER 
has been conducted. We simulated that if subsidies were eliminated for all but one atypical based on CATIE trial, a loss of value at $5 \%$ of class spending would be observed ${ }^{17}$.

The main conclusion of our analysis is that simplistic thinking about the impact of traditionally perceived CER may have adverse effects. However, this does not mean that public technology assessments in health care in general, or CER in particular, may not have a useful role to play. The analysis suggests several future research issues that we list here to enable a better understanding of that role. .

\section{Decentralized vs. Centralized Production of Evidence}

Our analysis of the impact of CER-responsive subsidies suggests that a better understanding is needed as to how CER should be stratified towards obtaining the right treatments for the right subpopulations rather than focused on a "best" treatment for all patients. It is recognized that "one size fits all" treatment evaluations may be harmful and the main remedy proposed has been sub-population analysis. However, simply doing a sub-population analysis for many demographic groups neither solves the problem (given within-group heterogeneity) nor is practical in terms of bureaucratic decision-making with many separate subgroups facing differential reimbursement.. A better understanding needs to be developed about when individual-level attempts to learn about treatment effects through trial and error ("decentralized patient controlled cross-over trials") dominate or is dominated by centralized evidence such as publicly funded CER. When heterogeneity clouds the applicability of centralized studies to individual patients, the "make or buy"-decision of generating evidence on person-specific treatment effects needs to be better understood. An individual ultimately cares about her own treatment effect, the question is how costly it is to learn that effect through personal consumption versus publicly funded CER.

\section{CER for Sequenced Care}

${ }^{17}$ Concerns about the implications of CER-responsive subsidy policies in the face of heterogeneous treatment effects cut across many other clinical scenarios. The literature is voluminous on the many other classes to which our analysis may generalize including, for example, the use of antipsychotics drugs in Alzheimer's disease (Schneider et al., 2006), use of antihypertensive drugs (Matchar et al., 2008) and the treatments for clinically localized prostate cancer (Wilt et al., 2008). 
Traditional RCTs that focus on intention-to-treat effects are not useful when there is sequencing of treatments over time with a first line therapy, second line therapy and so on. This is because RCTs generate marginal distributions of treatment responses. What would be more valuable to know would be conditional distributions of treatment responses of the second stage, conditional on failure of the first-stage. If there is dependence in treatment responses, as suggested by the data we considered from the CATIE trial, learning about the joint distribution is of great value (Basu, 2009). CER should be tailored to incorporate such dependence when trial and error of finding the right treatment for the right patient is of importance.

\section{Procedures vs. Medical Products as the Domain for Public CER}

Intellectual property on medical products such as drugs and devices implies strong incentives for manufacturers to get the right information generated about the quality of their products or the lack of quality of their competitors' products $^{18}$. This is in opposition to procedures which, without patents, have no owners with similar protective interests. In addition, many countries mandate quality evidence to be produced before marketing (in the US through the FDA). This suggests that a useful role for public subsidies of these activities would be for procedures and not products. This is supported by evidence showing that the share of private funding for technology assessments was higher for patented medical products than it was for generic products or procedures. Procedural CER is of importance for reducing health care variations documented by the Dartmouth Atlas, whereby it has been suggested that less cost-efficient regions could adopt the procedures of more cost-efficient regions. However, the spending implications of such procedural CER may not be as perceived when more cost-efficient care reduces prices but expands quantity.

\section{The Endogenous Nature of Pricing in response to Reimbursement Policy Based on CER}

A better understanding is needed of how optimal pricing of therapies responds to subsidy policies that are based on CER. Manufacturers will likely re-price products to become eligible for reimbursement in the wake of new evidence and subsidies. In particular, for our case of antipsychotics, the debate about whether second generation treatments should be reimbursed at par with first generation treatments is somewhat misguided. This is because it relies on the evidence prior to reimbursement change to argue that higher-priced second generation treatments are equally effective within their class, but less costeffective than lower-priced first generation treatments. However, prices after CER studies will adjust, depending on whatever the responsive subsidy rules are. Thus, endogenous pricing is central to any conclusion of appropriate reimbursement policy based on CER. Therefore, the cost-savings calculated

\footnotetext{
${ }^{18}$ A mitigating factor is that private incentives may under-produce CER when ex-ante losses to the funder from unfavorable results outweigh gains from favorable results.
} 
are likely an upper bound and should be contrasted to cost-savings that occur with a given reimbursement rule in place.

The implications for $R \& D$ and product approval

A special case of our analysis concerns the public technology assessments that occur through the approval process rather than the reimbursement process. Consider when the second treatment is one of three possibilities: the existing treatment that is already on the market, no treatment, or a placebo treatment. Now interpret the last treatment as the one being studied for potential marketing approval to enter the market. This is a special case of the framework above because when the investigated drug is a loser compared to the winner on the market, a lack of approval is an extreme form of a responsive subsidy that raises the price enough to completely eliminate all demand for the loser. In other words, investigating a drug and not approving it is equivalent to imposing a prohibitive tax for the loser of the study. This special case is important because the discussed implications about CER translate into R\&D implications through the FDA approval process. In particular, the FDA approval process is product-specific as opposed to being concerned with matching patients to the therapies that work best for each patient. Indeed, many patient groups often disagree with the outcomes of the FDA approval- or withdrawal process due to the heterogeneity discussed here; just as the perceived paradigm for CER is "one-size-fits-all", so is the existing paradigm for approval and withdrawal. We believe these unique R\&D implications of CER and the product approval process deserve more attention.

More generally, as a better understanding develops on these and related topics, we hope that improved evaluation can take place regarding the value of public technology assessments in general, and CER in particular. As it stands right now, there are no methods to quantitatively assess the impact of these activities and why they improve on private sector activities aimed at the same purpose. We hope that quantitative frameworks similar to the ones discussed here will help bridge that gap, making precise assessments of the value of public subsidies for technology assessments feasible and more common. Indeed, the indeterminate effect on cost-effectiveness of CER discussed suggests that the CER of CER needs to be better understood and deserves more attention by health economists. 


\section{Appendix: Estimates from CATIE analysis}

Table A1: Intention-to-treat effectiveness and cost estimates from CATIE data used for pre-CER policy

\begin{tabular}{|l|c|c|c|}
\hline \multicolumn{1}{|c|}{ Initial Assignment } & $\begin{array}{c}\text { Effect of initial assignment } \\
\text { on average monthly } \\
\text { changes in } \mathrm{QOL}^{+}\end{array}$ & $\begin{array}{c}\text { Effect of initial } \\
\text { assignment on average } \\
\text { monthly total costs } \\
\text { (drugs and services)* }\end{array}$ & $\begin{array}{c}\text { Effect of initial } \\
\text { assignment on costs of } \\
\text { antipsychotic drugs } \\
\text { only* }\end{array}$ \\
\hline Quetiapine & $0.0030(0.0006)^{*}$ & $\$ 1657$ & $\$ 415$ \\
Risperidone & $0.0028(0.0005)^{*}$ & $\$ 1529$ & $\$ 440$ \\
Olanzapine & $0.0030(0.0005)^{*}$ & $\$ 1428$ & $\$ 595$ \\
Perphenazine (typical) & $0.0028(0.0006)^{*}$ & $\$ 1139$ & $\$ 196$ \\
\hline
\end{tabular}

* Based on Rosenheck et al (2005), Supplemental Table C

Table A2: Estimated treatment effectiveness and costs stratified by continuers and discontinuers of initial treatment assignment, used for post-CER responsive policy.

\begin{tabular}{|c|c|c|c|}
\hline \multirow[t]{2}{*}{ Initial Assignment } & \multirow[t]{2}{*}{$\begin{array}{l}\text { Effect of initial assignment on average } \\
\text { monthly changes in QOL }\end{array}$} & \multicolumn{2}{|c|}{$\begin{array}{l}\text { Effect of initial assignment on average } \\
\text { monthly total costs ** }\end{array}$} \\
\hline & & $\begin{array}{c}\text { All Drugs \& } \\
\text { services }\end{array}$ & Services Only \\
\hline & \multicolumn{3}{|c|}{ AMONG THOSE WHO CONTINUED ON INITIAL ASSIGNMENT } \\
\hline \multirow{4}{*}{$\begin{array}{l}\text { Quetiapine } \\
\text { Risperidone } \\
\text { Olanzapine } \\
\text { Perphenazine (typical) }\end{array}$} & \multirow{4}{*}{$\begin{array}{l}0.0027(0.0008)^{*} \\
0.0031(0.0007)^{*} \\
0.0030(0.0009)^{*} \\
0.0029(0.0009)^{*}\end{array}$} & $\$ 1478$ & $\$ 962$ \\
\hline & & $\$ 1532$ & $\$ 970$ \\
\hline & & $\$ 1404$ & $\$ 758$ \\
\hline & & $\$ 960$ & $\$ 822$ \\
\hline & \multicolumn{3}{|c|}{ AMONG THOSE WHO DISCONTINUED ON INITIAL ASSIGNMENT } \\
\hline Quetiapine & $0.0019(0.001)$ & \multicolumn{2}{|c|}{-} \\
\hline Risperidone & $-0.0020(0.001)$ & \multicolumn{2}{|c|}{ - } \\
\hline Olanzapine & $0.0038(0.001)^{*}$ & \\
\hline Perphenazine (typical) & $0.0024(0.001)$ & \multicolumn{2}{|c|}{-} \\
\hline
\end{tabular}

Note: Joint test for treatment-time interaction for QOL effect among continuers not significant $(p=0.94)$;

Joint test for treatment-time interaction for QOL effect among discontinuers significant $(p=0.015)$

*P-value $<0.05$

*** Based on Rosenheck et al (2005), Supplemental Table D, crossovers excluded. 


\section{References}

Banthin, J.S., Miller, G.E. 2006. Trends in Prescription Drug Expenditures by Medicaid Enrollees, Medical Care, 44:I-27-I-35.

Basu, A. 2009. Economics of individualization in comparative effectiveness research and a basis for a patientcentered healthcare. Draft, University of Chicago.

Bruen, B., Ghosh, A. 2004. Medicaid Prescription Drug Spending and Use. Kaiser Commission on Medicaid and the Uninsured Issue Paper. http://www.kff.org/medicaid/upload/Medicaid-Prescription-DrugSpending-and-Use.pdf, accessed December 21, 2009.

Chernew, ME., Rosen, A., Fendrick, AM. Value-based insurance design. Health Affairs 2007; 26(2): w195-w203.

Federal Coordinating Council for Comparative Effectiveness Research. 2009. Report to the President and the Congress. June 30.

Fendrick, A.M., Smith, D.G., Chernew, M.E., Shah, S.N. A benefit-based copay for prescription drugs: patient contribution based on total benefits, not drug acquisition cost. Am J Manag Care ; 7:861867.

Gilmer, T.P., Dolder, C.R., Lacro, J.P., Folsom, D.P., Lindamer, L., Garcia, P., Jeste, D.V. 2004, Adherence to treatment with antipsychotic medication and health care costs among Medicaid beneficiaries with schizophrenia. The American Journal of Psychiatry, 161(4), 692-9.

Goldman, D., Philipson, T.J. Integrated Insurance Design in the Presence of Multiple Medical Technologies. American Economic Review 2007; 97(2): 427-432.

IOM Initial National Priorities for Comparative Effectiveness Research: Committee on Comparative Effectiveness Research Prioritization Board on Health Care Services, June 2009.

Kane, J.M. 2004. Tardive dyskinesia rates with atypical antipsychotics in adults: prevalence and incidence. Journal Clinical Psychiatry, 65(suppl 9), 16-20.

Leucht, S., Corves, C., Arbter, D., Engel, R.R., Li, C., \& Davis, J.M. 2009. Second-generation versus firstgeneration antipsychotic drugs for schizophrenia: a meta-analysis. Lancet, 373, 31-41.

Lewin Group. 2000. Access and Utilization of New Antidepressant and Antipsychotic Medications. Report submitted to The Office of the Assistant Secretary for Planning and Evaluation and The National Institute of Mental Health, U.S. Department of Health and Human Services. http://aspe.hhs.gov/health/reports/Psychmedaccess/.

Lenert, L., Sturley, A. P., Rapaport, M.H., Chavez, S., Mohr, P., Rupnow, M. 2004, Public preferences for health states with schizophrenia and a mapping function to estimate utilities from positive and negative syndrome scale scores. Schizophrenia Research, 71, 155-165.

Malani, A. and T. Philipson, (2010), "Government Regulation of Medical Product Safety and Innovation”, forthcoming, Handbook of Pharmaceuticals Markets, edited by P Danzon and S. Nicholson, Oxford University Press.

Matchar, D.B., McCrory, D.C., Orlando, L.A., Patel, M.R., Patel, U.D., Patwardhan, M.B., Powers, B., Samsa, G.P., Gray, R.N. 2008. Systematic Review: Comparative Effectiveness of AngiotensinConverting Enzyme Inhibitors and Angiotensin II Receptor Blockers for Treating Essential Hypertension. Annals of Internal Medicine 148(1), 16-29. 
Meltzer, H.Y. 2005. The metabolic consequences of long-term treatment with olanzapine, quetiapine and risperidone: are there differences?” International Journal of Neuropsychopharmacology, 8, 153-6.

Meltzer, H.Y. 2009. Atypical antipsychotic drugs have their merits. Lancet, 373, 1007.

NIMH Perspective on Antipsychotic Reimbursement: Using Results from CATIE. http://www.nimh.nih.gov/about/director/updates/2006/nimh-perspective-on-antipsychoticreimbursement-using-results-from-the-catie-cost-effectiveness-study.shtml (accessed September 17, 2009)

New York Times Editorial 2005. Comparing schizophrenia drugs. September 21.

Pauly, M. V., Blavin F.E. 2008. Moral Hazard in Insurance, Value-based Cost Sharing, and the Benefits of Blissful Ignorance. Journal of Health Economics, 27, 1407-1417.

Polinski, J. M., Wang, P. S., Fisher, M. A. 2007. Medicaid’s Prior Authorization Program And Access To Atypical Antipsychotic Medications. Health Affairs 26(3), 750-760.

Polsky, D., Doshi, J.A., Bauer, M.S., Glick, H.A. 2006. Clinical trial-based cost-effectiveness analyses of antipsychotic use. Am J Psychiatry, 163, 2047-56.

Rosenheck, R.A. et al. 2007. CATIE Investigator’s Educations Series.

Rosenheck, R.A. et al. 2006. Cost-effectiveness of Second Generation Antipsychotics and Perphenazine in a Randomized Trial of Treatment for Chronic Schizophrenia. American Journal of Psychiatry, 163(12), 2080-9.

Schnider, L.S., Tariot, P.N., Dagerman, K.S., Davis, S.M., Hsiao, J.K., Ismail, M.S., Lebowitz, B. D., Lyketsos, C.G., Ryan, J.M., Stroup, T.S., Sultzer, D.L., Weintraub, D., Lieberman, J.A., for the CATIE-AD Study Group. 2006. Effectiveness of Atypical Antipsychotic Drugs in Patients with Alzheimer's Disease. New England Journal of Medicine, 355(15), 1525-1538

Stinnett, A., Mullahy, J. 1998.Net Health Benefits: A New Framework for the Analysis of Uncertainty in Cost-Effectiveness Analysis. Medical Decision Making 18, S68-S80.

Soumerai, S.B., Law, M.R. 2007. Cost-effectiveness of schizophrenia pharmacotherapy. American Journal Psychiatry 164, 678.

Wilt, T.J., MacDonald, R., Rutks, I., Shamliyan, T.A., Taylor, B.C., Kane, R.L. 2008, Systematic Review: Comparative Effectiveness and Harms of Treatments for Clinically Localized Prostate Cancer. Annals of Internal Medicine 148(6), 435-448.

Weiden, P.J., Oltson, M. 1995. Cost of Relapse in Schizophrenia. Schizophrenia Bulletin, 21(3), 419-429.

Wu, E.Q., Shi, L., Birnbaum, H., Hudson T., Kessler, R. 2006. Annual prevalence of diagnosed schizophrenia in the USA: a claims data analysis approach. Psychological Medicine 36, 1535-1540. 
